\title{
PEG Conjugation Moderately Protects Adeno-Associated Viral Vectors Against Antibody Neutralization
}

\author{
Gary K. Lee, ${ }^{1}$ Narendra Maheshri, ${ }^{1}$ Brian Kaspar, ${ }^{2}$ David V. Schaffer ${ }^{1}$ \\ ${ }^{1}$ The Department of Chemical Engineering and, \\ The Helen Wills Neuroscience Institute, The University of California, Berkeley, \\ California 94720; telephone: 510-643-5963; fax: 510-642-4778; \\ e-mail: schaffer@cchem.berkeley.edu \\ ${ }^{2}$ Columbus Children's Research Institute, Columbus, Ohio
}

Received 7 February 2005; accepted 6 April 2005

Published online 3 June 2005 in Wiley InterScience (www.interscience.wiley.com). DOI: 10.1002/bit.20562

\begin{abstract}
AAV gene therapy vectors have significant clinical promise, but serum neutralization poses a challenge that must be overcome. We have examined the potential of conjugating the AAV surface with activated polyethylene glycol chains to protect the vector from neutralizing antibodies. Two key parameters were investigated: the polymer chain size and the PEG:lysine conjugation ratio. Transduction data revealed that the vector is fully infectious until a critical PEG conjugation reaction ratio was exceeded, and this critical level was found to vary with polymer chain size. At this key conjugation ratio, however, particles were moderately protected from serum neutralization, 2.3-fold over unmodified vector, demonstrating that there is a small window of PEGylation for which particles are still fully infective and benefit from antibody protection. TEM results and structural analysis indicate that the drop of infectivity as the PEG concentration is increased beyond the critical conjugation ratio may be due to a combination of steric interference with viral regions necessary for infection as well as reaction at important lysine residues. However, this first study analyzing the potential of PEG to protect AAV from serum neutralization shows that the approach has promise, which can be further enhanced if the locations of PEG attachment can be more finely controlled. (c) 2005 Wiley Periodicals, Inc.
\end{abstract}

Keywords: AAV; viral vector; polyethylene glycol; PEG; conjugation; neutralizing antibody; neutralizing epitope

\section{INTRODUCTION}

AAV is a helper-dependent human parvovirus with a $4.7 \mathrm{~kb}$ single-stranded DNA genome packaged within an icosahedral capsid. The genome contains two open-reading frames, rep, which encodes four proteins that regulate viral replication, and cap, which codes for three partially overlapping

Correspondence to: David V. Schaffer

Contract grant sponsors: NIH T32 (to GL); NSF Graduate Fellowship (to NM); Whitaker Foundation Biomedical Engineering Research Grant (to DVS)

Contract grant number: EB003007-01 structural proteins, VP1-3. Sixty subunits of VP1-3 selfassemble in an approximate stoichiometric ratio of $1: 1: 18$ to generate a viral capsid that is $\sim 26 \mathrm{~nm}$ in diameter (Bueler, 1999; Xiao et al., 1997). Although a number of AAV serotypes have been identified (Gao et al., 2002, 2003), we focus on the best characterized variant and the only one to be utilized in clinical trials (Kay et al., 2000), AAV serotype 2 (Gao et al., 2002; Rutledge et al., 1998; Samulski et al., 1989a).

Vectors based on adeno-associated virus show significant promise at both the preclinical and clinical level as delivery agents for human gene transfer. Recombinant AAV (rAAV) vectors are non-pathogenic, have the ability to transduce a wide range of tissues (Flannery et al., 1997; Herzog, 2004; Herzog and High, 1999; Kaspar et al., 2002b; Miao et al., 2000; Takeda et al., 2004; Tenenbaum et al., 2004), and are capable of stable integration or episomal maintenance resulting in long-term transgene expression (Afione et al., 1996; Duan et al., 1998; Flotte et al., 1994; Kearns et al., 1996; Nakai et al., 1999). Over $90 \%$ of the human population is seropositive for anti-AAV2 antibodies, with no associated disease. However, because of this large prevalence of natural exposure to AAV within the population, rAAV vector delivery can be severely compromised by pre-existing host immunity. In particular, several studies estimate between 30 and $70 \%$ of the population harbor antibodies capable of neutralizing rAAV infection (NAb's). Dramatic inhibition of AAV vector gene delivery by NAb's has been demonstrated in numerous animal studies (Halbert et al., 1998, 2000; Hildinger et al., 2001; Manning et al., 1998). For example, Mandel et al. (Peden et al., 2004) and Sanftner et al. (2004) recently reported that pre-existing humoral immunity results in a moderate to significant loss in transduction efficiency even in the brain, considered an immune privileged tissue.

One potential approach to overcome the problem of preexisting immunity is the use of alternate AAV serotypes (Hildinger et al., 2001; Peden et al., 2004; Rabinowitz et al., 2002; Xiao et al., 1999). However, a significant fraction of the 
human population appears to be seropositive for AAV1-6 (Sun et al., 2003), and there is some reluctance to advance serotypes other than AAV2 to the clinic until they are better characterized. Furthermore, even if a patient has not previously been infected to a given serotype, it is likely that they will seroconvert after their first exposure to high titer vector, rendering vector readministration problematic (Halbert et al., 1998, 2000; Hildinger et al., 2001; Manning et al., 1998). For these reasons, there is a need to design strategies to protect AAV2 from neutralization by host antibodies.

Peptide-scanning and phage display experiments have been utilized to identify numerous dominant antigenic regions of the AAV2 capsid, i.e., epitopes that several neutralizing antibodies apparently bind (Moskalenko et al., 2000; Wobus et al., 2000). To prevent antibody binding and subsequent neutralization, the surface properties of these, and likely other, regions of the AAV capsid must be altered. One approach to modulate the surface is by genetic modification, thereby generating mutant viral particles with altered antigenic surface properties. Researchers have identified multiple regions within the capsid protein that can tolerate small peptide insertions and have taken advantage of this capability to engineer targeted AAV vectors (Girod et al., 1999; Rabinowitz et al., 1999; Shi et al., 2001; Wu et al., 2000). Based on these studies, Huttner et al. recently showed that mutants with peptide insertions in or near the A20-4 and C37-3 epitopes exhibited $70 \%$ reduced affinity to antibodies and demonstrated an approximately $6-8$ fold protection from antisera in in vitro transduction studies. However, despite this improvement in antibody evasion, the mutants suffered considerable (1,000-fold) losses in infectivity (Huttner et al., 2003). Furthermore, genetic modification may not address the challenge of vector readministration.

An alternative approach is to alter the capsid surface by chemical modification. Covalently coating proteins with biologically inactive polymers, in particular polyethylene glycol (PEG), has been a well-established approach for "stealthing" biomolecules from the immune system. For example, over the past several decades the "PEGylation" of protein therapeutics such as IFN, TNF $\alpha$, and GM-CSF has been demonstrated to significantly increase their circulatory half-life (Edwards et al., 2003; Luxon et al., 2002; Malik et al., 1992). In addition, over the past 5 years researchers have begun to explore the feasibility of conjugating PEG to viral vectors. O'Riordan et al. PEGylated adenoviral vectors, and the resulting vehicles exhibited transduction efficiencies elevated by approximately $60 \%$ in vitro and $50 \%$ in vivo in the presence of neutralizing serum (O'Riordan et al., 1999). In another study, Croyle et al. demonstrated that PEGylated adenoviral vectors showed a 10-fold enhancement in transduction in the presence of neutralizing antibodies, as well as improved thermostability (Croyle et al., 2000). Subsequent work by Croyle et al. indicated that PEG-conjugated adenoviral vectors had the additional benefit of reducing the initial immune response to the vehicle in vivo, as well as significantly improved transduction efficiencies during readministration to the lung and liver (Croyle et al., 2001, 2002).
In addition to adenoviral vectors, PEGylation of vesicular stomatitis virus $\mathrm{G}$ protein pseudotyped lentiviral vector provided a 20-fold resistance to antiserum and extended circulatory half-life by a factor of 5 with no observable loss in titer (Croyle et al., 2004). The polymer poly-[N-(2hydroxylpropyl)methacrylamide] (pHPMA) has also been utilized to coat adenoviral vectors and yielded a fivefold reduction in antibody neutralization compared to unmodified vectors (Fisher et al., 2001).

To our knowledge, we present the first investigation of the ability of the PEGylation to protect rAAV vectors from antibody neutralization. Specifically, we have systematically varied the polymer length and find that within a narrow range of PEG:lysine reaction ratios, PEG moderately protects AAV from neutralizing serum and does not compromise viral infectivity. However, at higher ratios viral infectivity is significantly reduced. Electron microscopy analysis demonstrates that PEGylation increases the particle size and yields insights into potential mechanisms of the loss in infectivity. This work demonstrates that PEGylation has significant promise for effectively protecting AAV vectors, particularly if the conjugation chemistry can be further controlled.

\section{MATERIALS AND METHODS}

\section{Adeno-Associated Viral Vector Production}

Recombinant AAV2- $\beta$ Gal vector was produced as we have previously described (Kaspar et al., 2002a,b, 2003; Lai et al., 2003). Briefly, virus was generated by calcium phosphate transient triple transfection of the vector plasmid carrying an insert encoding bacterial $\beta$-galactosidase $(\beta \mathrm{Gal})$, the pAAV/Ad8 helper plasmid (Samulski et al., 1989b), and an adenoviral helper plasmid into HEK-293 cells (ATCC, Manassas, VA). AAV particles were purified by $\mathrm{CsCl}$ density centrifugation and heparin column purification as previously described (Kaspar et al., 2002a,b, 2003; Lai et al., 2003). Viral genome titer was determined by quantitative PCR following extraction of vector DNA by proteinase $\mathrm{K}$ digestion (Invitrogen, Carlsbad, CA). Quantitative PCR of the viral genomes was conducted on a Bio-Rad iCycler using SYBR Green dye (Molecular Probes, Eugene, OR) and primers specific for the CMV promoter, ATGGTGATGCGGTTTTGGCAG and GGCGGAGTTGTTACGACATTTTGG. Linearized vector plasmid was used as the standard.

\section{AAV PEGylation}

Polyethylene glycol chains with electrophilic succinimidyl propionic acid (SPA) groups were chosen for reaction with viral lysine residues. Three chain sizes were used: SPA-2000, SPA-5000, and SPA-20000 (Nektar, San Carlos, CA). BiotinPEG-NHS was also purchased from Nektar. Reactions were conducted in HEPES buffered saline (HBS) (50 mM HEPES (Fisher Scientific, Pittsburgh, PA), $150 \mathrm{mM} \mathrm{NaCl}, 0.1 \%$ Tween-20, pH 7.4). Activated SPA PEGs were dissolved in 
HBS at $10 \mathrm{nM}$ immediately prior to use, and serial dilutions were generated for PEGylation of AAV at various PEG:lysine ratios. In calculating the molar PEG:lysine ratio, the lysine count was estimated by multiplying the total number of lysine residues in VP3 (18) by sixty (as the contribution of additional lysine residues from VP1 and VP2 are minimal). Two microlitres of viral stock $\left(10^{12}\right.$ viral genomes $\left./ \mathrm{mL}\right)$ and appropriate quantities of activated SPA PEG solution were mixed in $20 \mu \mathrm{L}$ total volume, followed by a $3 \mathrm{~h}$ incubation at room temperature and storage at $4{ }^{\circ} \mathrm{C}$ prior to use. As the presence of unconjugated, soluble PEG did not affect viral infectivity, the virus was not separated from this excess PEG, though gel filtration could readily be performed in subsequent studies. Rasmol and Swiss-PDB viewer were used to annotate known antigenic regions and lysine residues on a reconstruction of the viral capsid based on the solved structure of VP3 (Xie et al., 2002a).

To detect PEGylation, AAV was incubated with BiotinPEG-NHS, and $\sim 10^{10}$ particles were subjected to SDSPAGE and transferred to a nitrocellulose membrane (Bio-Rad, Hercules, California). Biotinylated/PEGylated viral protein was imaged with streptavidin-horseradish peroxidase (HRP) and ECL Western blotting reagent (Amersham Bioscience, Piscataway, New Jersey).

\section{Neutralizing Serum and Cell Culture}

Polyclonal sera containing neutralizing antibodies to AAV2 were generated in New Zealand White rabbits following $\mathrm{NIH}$ guidelines for vertebrate animal care. After collection of a sample of pre-immune serum, $5 \times 10^{9}$ purified AAV- $\beta$ Gal particles were injected subcutaneously into each hindlimb muscle using TitreMax as the adjuvant (CytRx, Norcross, GA).

For vector transduction, $2 \times 10^{5} \mathrm{HEK}-293 \mathrm{~T}$ cells in $100 \mu \mathrm{L}$ total volume were plated per well in a 96 well plate. One microlitre of unmodified AAV or PEGylated AAV was added to each well, and the mixture was gently shaken for $15 \mathrm{~min}$. After a $24 \mathrm{~h}$ incubation, cells were lysed, and portions of the lysate samples were added to $100 \mu \mathrm{L}$ of $o$-nitrophenyl- $\beta$-Dgalactopyranoside (ONPG) cocktail. The ONPG cocktail was composed of $77 \mu \mathrm{L}$ of $0.1 \mathrm{M}$ sodium phosphate $\mathrm{pH} 7.5$

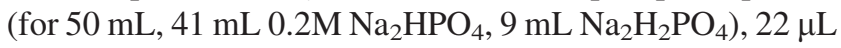
of $4 \mathrm{mg} / \mathrm{mL}$ ONPG $(4 \mathrm{mg} / \mathrm{mL}$ ONPG in $0.1 \mathrm{M}$ sodium phosphate, with $2 \mathrm{mM} \beta$-mercaptoethanol), and $1 \mu \mathrm{L}$ of $100 \times \mathrm{Mg}$ solution $(0.1 \mathrm{M}$ magnesium chloride, $4.5 \mathrm{M} \beta$ mercaptoethanol). After a $30 \mathrm{~min} \beta$-galactosidase reaction, absorbance was measured in a $\mu$ Quant spectrophotometer (Bio-Tek Instruments, Winooski, VT). Triplicate measurements were taken for each condition, and results were analyzed by a Student $t$-test.

\section{Negative Staining Transmission Electron Microscopy (TEM)}

Copper grids were coated with Formvar (polyvinyl formal) and glow discharged to render the surface hydrophilic before use. Viral vector samples were loaded onto the grid, dried, and incubated for 2 min with $10 \mu \mathrm{L}$ of $2 \%$ uranyl acetate. Images were collected using a FEI Tecnai 12 (120KV) tunneling electron microscope.

\section{RESULTS}

\section{AAV PEGylation}

As shown in Figure 1, based upon Xie et al. (2002a), there are a number of lysine residues on or near the AAV capsid surface. To determine whether the amino groups of these lysines are accessible for electrophilic substitution, we reacted AAV particles with a bifunctional PEG chain, biotin-PEG-NHS at a molar ratio of $10^{3}: 1$ PEG:lysine. The Biotin-PEG-NHS is a PEG chain flanked by a biotin group and SPA, an amine reactive group that crosslinks the PEG to lysine residues. The biotin-PEG conjugated AAV capsid was detected by
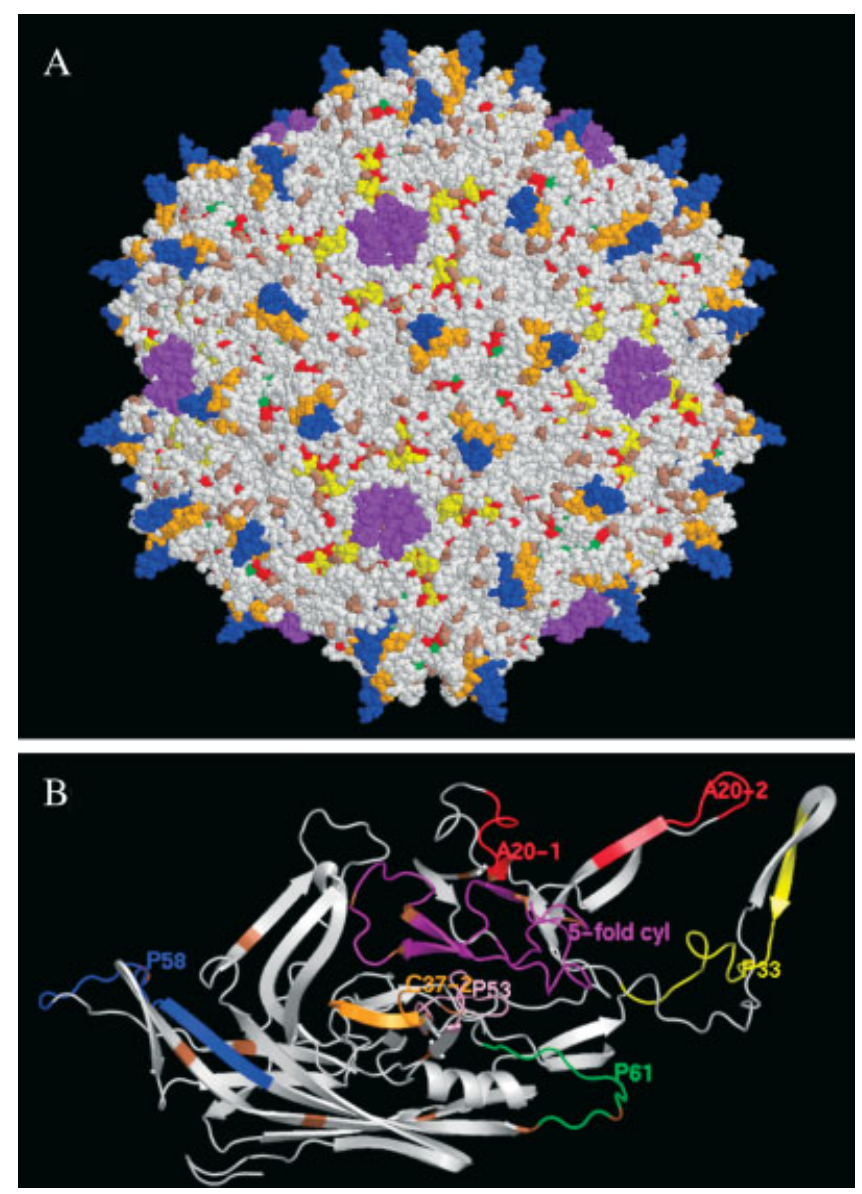

Figure 1. A: A 3-dimensional model of the AAV capsid, based upon Xie et al. (Xie et al., 2002a), with the nitrogen atoms of the primary amines labeled by enlarged brown spheres. Some of the primary amines clearly colocalize with known antigenic regions. B: However, there are regions that do not have accessible primary amines, such as the P58 threefold spike loop (blue). In both images, previously identified neutralizing epitopes are shown in color: yellow, peptide 33 canyon epitope; purple, fivefold cylinder; pink, P53; blue, P58 threefold spike in loop 3; green, P61-62, threefold spike in loop 3 (Moskalenko et al., 2000); as well as red, A20 monoclonal antibody; orange, C37 monoclonal antibody (Wobus et al., 2000). 
Western blot using streptavidin-HRP, demonstrating that some of surface lysine residues can be PEGylated (Fig. 2A).

\section{Infectivity of PEGylated AAV Particles}

We next assessed the effect of PEGylation on viral infectivity. Ideally, the PEG should shield as much of the capsid surface from neutralizing antibodies as possible without compromising the transduction efficiency of the vector. Two parameters were varied, the PEG molecular weight and molar ratio of reactive PEG molecules to lysine residues. The infectivity of rAAV particles coated with different PEG chains (MW 2,000, 5,000 , and 20,000, corresponding to 45, 114, and 455 ethylene oxides on average) at five different PEG:lysine ratios $\left(1: 1,10: 1,10^{2}: 1,10^{3}: 1\right.$, and $\left.10^{4}: 1\right)$ was assayed by a determining transduction efficiencies on HEK 293 cells. In parallel, PEG reagent was quenched by an excess of Tris buffer and added to $\mathrm{AAV}$ at a concentration corresponding to the highest PEG:lysine ratio and did not ever affect viral infectivity (data not shown). As a result, all experiments were conducted without separating unreacted PEG from virus, though future work such as animal studies could include a separation step based on gel filtration or affinity chromatography.

At lower PEG:lysine ratios, the transduction of rAAV particles conjugated to lower molecular weight PEG chains $(2,000$ and 5,000) demonstrated a slight but statistically insignificant decrease (Fig. 2B). However, between PEG: lysine ratios of 1,000 and 2,500, there was a sharp drop in infectivity, though the virus conjugated with the PEG 2,000 MW chain still exhibited moderate infectivity at the 2,500 PEG:lysine ratio. The AAV particles conjugated to the larger MW 20,000 chains showed the same qualitative trend. However, the point at which substantial inhibition occurred was shifted toward lower PEG:lysine ratios as the polymer molecular weight polymer increased. We define this impor- tant threshold as the critical conjugation reaction ratio, the highest PEG ratio in our conjugation reaction that still yielded highly infective virus. It is possible that this behavior is due to a mixture of PEGylated and un-PEGylated virus, though this is unlikely both because of the very high PEG:lysine ratios in the reaction, as well as the fact that the virus at the critical conjugation ratio is partially shielded from antibody neutralization (see below).

\section{Protection From Antibody Neutralization}

Several lots of commercially available anti-AAV capsid polyclonal antibodies were analyzed and not found to provide consistent levels of viral neutralization (R\&D Systems). Therefore, anti-AAV neutralizing serum was generated in New Zealand White rabbits. A Western blot of AAV particles using the rabbit serum for primary detection demonstrated that the serum contains anti-AAV antibodies (data not shown). We next determined that these antibodies were capable of inhibiting AAV transduction by infecting HEK $293 \mathrm{~T}$ cells with rAAV- $\beta$ gal that was preincubated with varying amounts of serum (Fig. 3A). In particular, incubation of rAAV- $\beta$ gal particles with $1 \%(\mathrm{v} / \mathrm{v})$ serum for $30 \mathrm{~min}$, followed by addition of the mixture to HEK 293T cells, reduced transduction by $50 \%$, and incubation with $6 \%(\mathrm{v} / \mathrm{v})$ serum resulted in a greater than $95 \%$ knockdown in AAV transduction. This level of neutralization is comparable to that reported for many human sera samples (Moskalenko et al., 2000). In contrast, incubation with serum collected from the same animal prior to immunization did not inhibit AAV gene delivery at any concentration.

The ability of conjugated PEG to protect AAV from antiserum neutralization was assayed by transducing HEK-293T cells in the presence of varying amounts of the serum. We did not observe protection from neutralizing antibody with the MW 20,000 conjugates at any conjugation ratio or

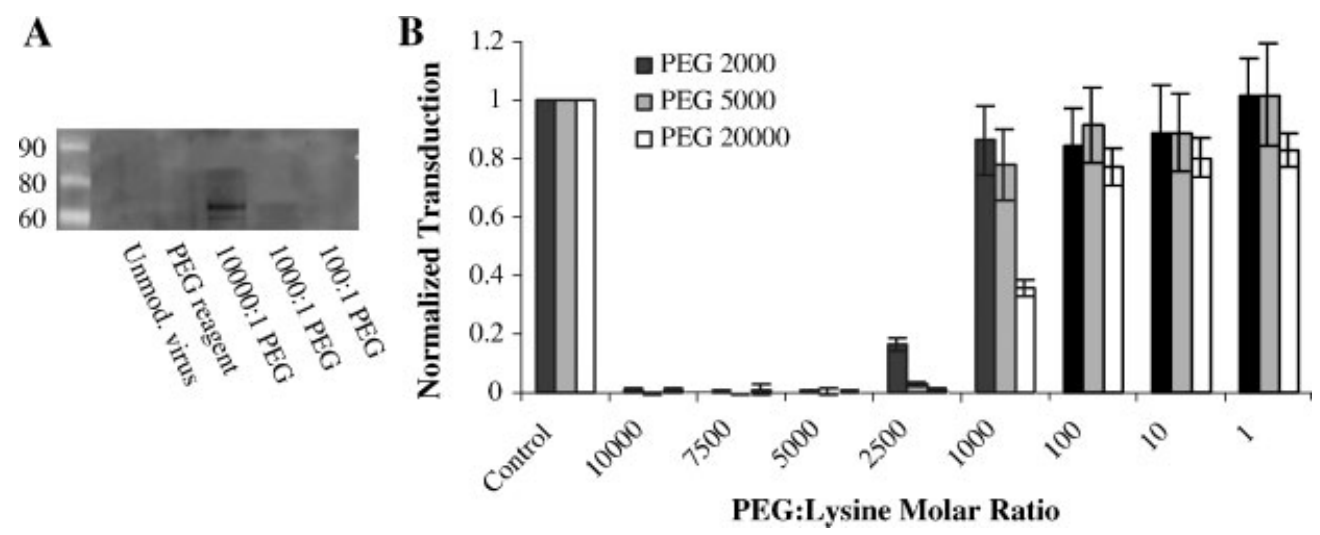

Figure 2. A: Demonstration of AAV PEGylation. AAV particles were reacted with biotin-PEG and subjected to SDS-PAGE and detection using streptavidin HRP. Control lanes with only unmodified virus or PEG reagent showed no bands, whereas virus incubated with the reagent at the two higher ratios showed PEG signals at molecular weights corresponding to VP3 (66 kDa) and VP2 faintly (80 kDa). No bands were detected for VP1 (92 kDa) or for the lowest PEG ratio. B: Transduction efficiencies of PEGylated AAV- $\beta$ Gal. Vector was PEGylated with different molecular weight PEG at the ratios described and was subsequently incubated with 293 cells. After $24 \mathrm{~h}, \beta$-galactosidase activity was quantified and normalized to that mediated by unmodified particles. An abrupt decline in titer was observed as the molar ratio of PEG:total lysines reached a key threshold. This key molar ratio of PEGylation apparently shifted towards lower PEG ratios as the polymer molecular weight increased. Control experiments with unmodified particles mixed with equivalent amount of hydrolyzed PEG molecules were conducted, and the presence of hydrolyzed PEG had no effect on AAV transduction (data not shown). 


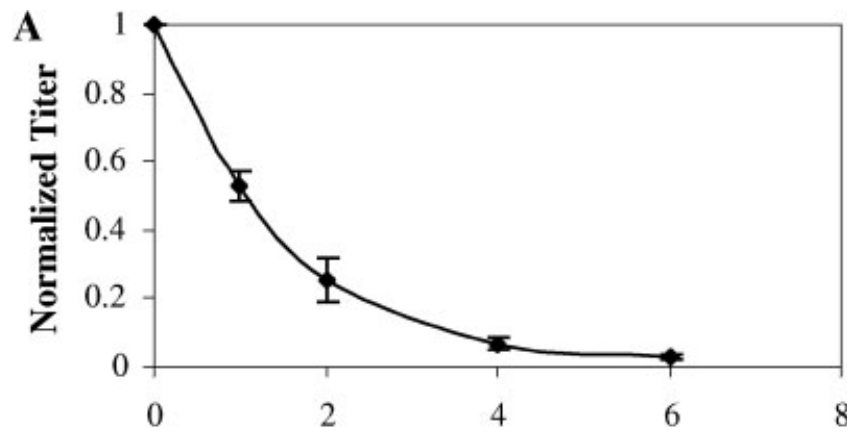

Percent Primary Serum
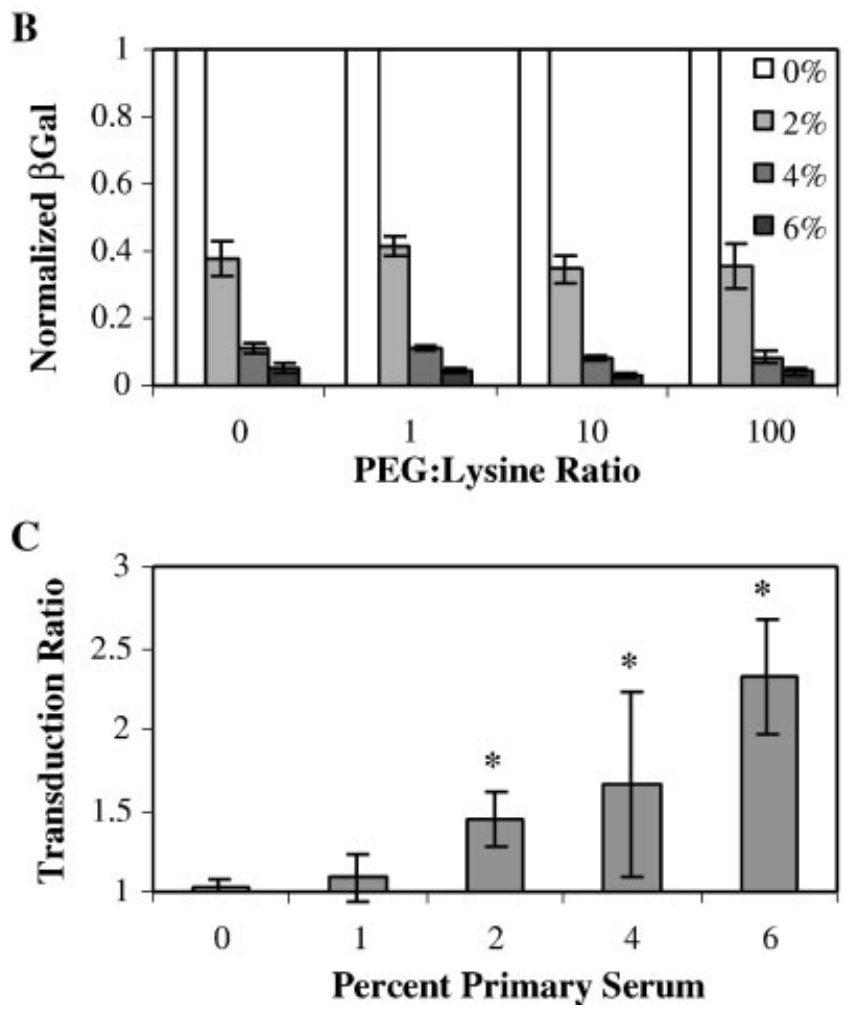

Figure 3. A: Inhibitory activity of the primary neutralizing serum. Virus was mixed with increasing concentrations of serum, followed by incubation with 293 cells. $\beta$-galactosidase activity was quantified and normalized to the $0 \%$ serum data point. B: At lower PEG:lysine reaction ratios ranging from 1:1 to 100:1, PEG 2000 does not protect at any serum concentration. Transduction was conducted at a MOI of 50 in the presence of $0-6 \%$ rabbit anti-AAV serum. C: PEG 2000 Protection. Transduction of HEK-293T cells with unmodified vector and vector conjugated with MW 2,000 PEG at the critical conjugation stoichiometry $(1,000: 1)$ was conducted to assay for protection from antibody neutralization, and the $\beta$-galactosidase activity was normalized to that for non-PEGylated particles at $0 \%$ serum. Protection is observed at $2 \%, 4 \%$, and $6 \%$ serum, and $*$ denotes a statistically significant difference from the $0 \%$ serum sample $(P<0.05)$.

concentration of serum (data not shown). Furthermore, at low conjugation ratios of PEG 2000 and 5000, the infectivity of both conjugated and unmodified control virus decreased equally, indicating that this level of PEGylation did not protect against neutralization (Fig. 3B). However, rAAV particles PEGylated with MW 2,000 PEG at the critical conjugation ratio $10^{3}: 1$ (PEG:lysine) showed moderate but statistically significant protection of AAV from serum neutralization at serum concentrations $>1 \%$ (Fig. 3C). Specifically, the transduction efficiency of the PEGylated virus was 1.5-fold, 1.7-fold, and 2.3-fold higher than unmodified virus at 2,4 , and $6 \%$ serum, respectively $(P<0.05)$. The degree of PEG protection therefore progressively increased as additional serum was added. It is possible that as the serum concentration increased, the complex mixture of polyclonal antibodies bound additional epitopes on the unprotected particles and thereby provided the PEG with additional opportunities to protect the particle. Similar results were observed with PEG 5000 (data not shown).

\section{Transmission Electron Microscopy Characterization}

We next imaged PEGylated virus by transmission electron microscopy as an initial attempt to examine the mechanisms by which PEGylation conferred moderate protection from anti-AAV serum at the critical conjugation ratio, as well as reduced the viral infectivity at high ratios. Based on these images, the particle sizes of different conjugated viral vectors were quantified (Fig. 4). Unmodified virus appeared as hexagonal particles $\sim 26 \mathrm{~nm}$ in diameter, as previously reported (Luo et al., 1988; Xie et al., 2002a). In addition, particles conjugated with the lower molecular weight (2,000 and $5,000)$ polymers at molar ratios at or below the critical conjugation ratio appeared essentially identical, both in shape and size, to the unmodified particles (Fig. 4). Intriguingly, at the molar ratio of $10^{4}: 1$, we observed a significant increase in particle size from a diameter from 26 to $34 \mathrm{~nm}$ accompanied by a slightly irregular shape. It is notable that the loss in viral infectivity also occurs between a PEG:lysine molar ratio of $10^{3}$ and $10^{4}$.

In contrast to the PEG 2000 and 5000 results, the particle size of the MW 20,000 conjugated particles increased from $26 \mathrm{~nm}$ in diameter to $38 \mathrm{~nm}$ regardless of the PEG:lysine molar ratio (varied from $1: 1$ to $10^{3}: 1$ ). In addition, the shape of the PEG 20000 conjugated particles changed significantly from a hexagonal to rough and amorphous. Notably, viral aggregation was not observed at any PEG:lysine ratios or polymer sizes.

\section{DISCUSSION}

A number of studies have demonstrated that host immune neutralization of AAV vector can significantly reduce transduction efficiency. A substantial portion of the population possesses pre-existing humoral immunity toward AAV vectors (Erles et al., 1999; Moskalenko et al., 2000; Sun et al., 2003; Walz et al., 2001; Xiao et al., 1999), and vector readministration will be problematic even for patients not previously exposed to the virus (Halbert et al., 1998, 2000; Hildinger et al., 2001; Manning et al., 1998). One study has genetically modified the AAV capsid by insertion of peptides at previously identified amino acid positions, but this evasion of antibody binding comes at the cost of significantly reduced vector infectious titer (Huttner et al., 2003). We have recently 
A
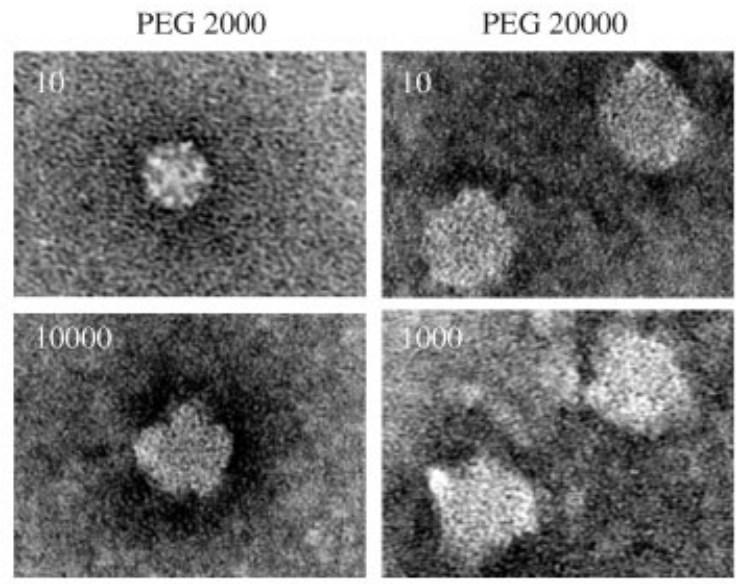

B
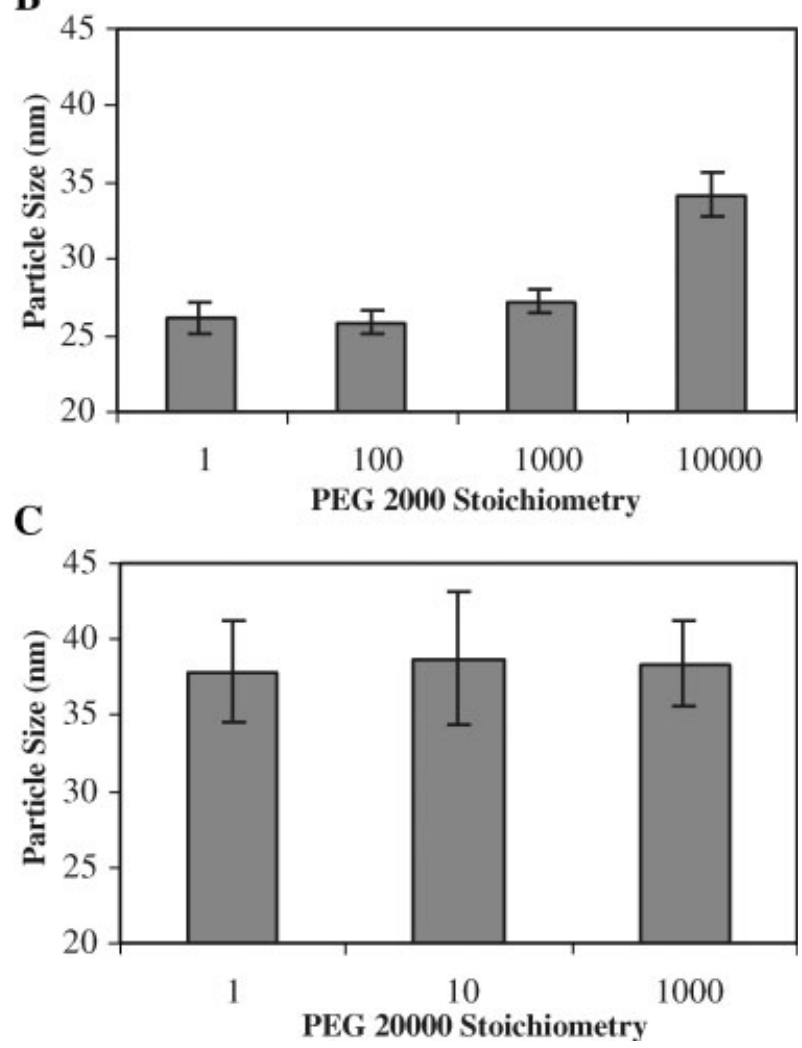

Figure 4. A: TEM images of negatively stained, PEG-conjugated AAV particles. B: Particle sizes for AAV conjugated with PEG 2000 over a range of stoichiometries, where the average and standard deviation of ten particles is shown. C: Particle sizes for AAV conjugated with PEG 20000. Particles were conjugated at different molar ratio of PEG:lysine, and the size and shape of the particles were the same as unmodified particles until the molar ratio exceeded the critical conjugational stoichiometry.

successfully generated AAV2 variants with randomly located point mutations that enable them to evade serum neutralization (Maheshri, Koerber, Kaspar, and Schaffer, manuscript submitted); however, even these mutants will likely elicit a unique immune response and therefore be neutralized upon readministration.

In this work, we have chemically modified the properties of the viral surface by conjugating activated PEG chains to exposed amine residues. PEG had been widely used as a coating to generate biocompatible surfaces that are nonimmungenic, nonantigenic, and resist protein adsorption (Alcantar et al., 2000; Kingshott and Griesser, 1999; Malmsten and Van Alstine, 1996). The molecular basis of the protein repellant properties of PEG is reportedly attributed to a number of different interactions: steric repulsion due to the polymer chain, repulsion due to the presence of a hydration shell around the polymer chain, and/or electrostatic repulsion stemming from the polar monomeric units (Chapman et al., 2000; Harris and Zalipsky, 1997; Jeon and Andrade, 1991; Jeon et al., 1991; Lee and Schaffer, 2003). For protein PEGylation, various types of crosslinking chemistry have been evaluated (Emoto et al., 1996; Kingshott et al., 2002; Roberts et al., 2002; Veronese, 2001; Veronese and Harris, 2002). In addition, PEGylation of therapeutic proteins such as interferon and tumor necrosis factor has been demonstrated to improve their pharmacokinetic profiles (Bailon et al., 2001; Kozlowski and Harris, 2001; Tsunoda et al., 1999; Yoshioka et al., 2004). More recently, PEGylation of adenoviral vectors has been shown to improve their transduction efficiency in the presence of neutralizing antibodies, both in vitro and in vivo (Croyle et al., 2000; O'Riordan et al., 1999).

In this initial study of AAV PEGylation, we anticipated that the greater the extent of PEGylation of the capsid surface, the less likely antibodies would be able to bind and neutralize the particles. However, in parallel viral infectivity could be increasingly compromised due to inhibition of binding to cell surface receptors or subsequent steps in cell entry. To determine whether there may be an intermediate range that confers antibody protection yet maintains high infectivity, we investigated the importance of two key conjugation parameters: the molecular weight of PEG used for PEGylation and the molar ratio of PEG to capsid lysine residues during the conjugation reaction. These parameters correspond roughly to the length and number of PEG molecules attached to the capsid surface. We found that for all chain lengths, transduction efficiency was compromised only when a critical PEG:lysine conjugation ratio was exceeded. In the presence of NAb's and at this critical ratio, rAAV particles conjugated with PEG 2000 showed a moderate (2.3-fold) increase in transduction efficiency relative to unprotected vector. Interestingly, vector conjugated with molecular weight 20,000 PEG was completely blocked by NAb's at all PEG:lysine ratios, including ones at or below it critical conjugation ratio. Together, these results indicate that there does exist a small range where the $\mathrm{AAAV}$ particle is decorated with enough PEG molecules that the antibody neutralization is inhibited to a greater extent than transduction efficiency. The existence and width of this range is dependent on PEG chain length.

The extent of both reduced viral infectivity and reduced antibody neutralization is directly related to where the PEG molecules attach to the capsid and how large a surface area they "cover." There is a likely a broad spectrum of lysine reactivity, which depends upon both the steric accessibility of the amino group and its local $\mathrm{pK}_{\mathrm{a}}$ (determined by the 
biochemical nature of the neighboring amino acid residues). Depending on the rate of SPA reaction with the amines vs. the rate of the competing hydrolysis reaction, the less reactive amines within this spectrum may not be conjugated until a sufficient concentration of the PEG is present. If some of these lysines reside in regions important for viral function, the viral infectivity would then decrease as the PEG:lysine ratio increases, as observed (Fig. 2). Similarly, if some of these lysines are in regions important for protection, the extent of shielding from NAb's should increase as the PEG:lysine ratio is raised. As a result of these competing factors, while protection from serum neutralization was observed at a ratio of $10^{3}$ for PEG 2000 and 5000, it was not possible to further increase this level without compromising viral infectivity. It is therefore important to consider the potential mechanisms for the viral infectivity loss to determine whether future efforts can overcome this concern.

There are two potential mechanisms for the infectivity drop: the loss of key lysines and/or steric coverage of key surface regions necessary for cellular infection. The first possibility is that PEGylation of some key primary amines, which converts them to amide residues, is likely detrimental to proper capsid protein function during cell binding and entry. AAV2 utilizes heparan sulfate proteoglycans (HSPG) as its primary cell surface receptor (Summerford and Samulski, 1998), and Wu et al. have shown that mutations of several lysine residues (K527, K532, K544) to alanines yield non-infectious or partially infectious virus, whereas other residues tolerated mutation (K549, K556, K620) (Kern et al., 2003; Opie et al., 2003; Wu et al., 2000). Likewise, chemical modifications of certain key lysine residues are likely to inactivate the viral particles.

Second, it is possible that steric coverage of key regions of the viral surface necessary for infectivity could also potentially reduce viral infectivity. For example, we observed that virus modified with PEG 20000 molecular weight exhibited a more rapid decrease in infectivity with increasing
PEG:lysine as compared to PEG 2000 and 5000 (Fig. 2), as well as dramatically larger and more irregularly shaped particles even at very low ratios (Fig. 4). However, if the system could be engineered so that PEGylation interferes only with HSPG binding and not subsequent steps in cell entry, then PEG may offer the potential for targeted gene delivery by blocking native tropism and presenting alternate targeting ligands.

Despite the fact that high PEG:lysine levels compromised infectivity, there was a narrow window of ratios in which protection was conferred. Moskalenko et al. (2000) and Wobus et al. (2000) have mapped the binding epitopes of several AAV2 neutralizing antibodies, and protecting the virus antibody binding would hinge upon the PEGylation of lysine residues sufficiently close to these and other epitopes for the PEG to repel the antibody. The Flory radius $R_{\mathrm{F}}$ of free polymer in solution can be estimated by $R_{\mathrm{F}}=C * N^{3 / 5}$ (Flory and Fisk, 1966), where $C$ is the effective "bond" length and $N$ is the statistical number of monomers. For PEG, the constant $C$ was found to be $3.5 \AA$ (Rex et al., 1998), and for MW 2000 PEG the $R_{\mathrm{F}}$ can therefore be estimated as approximately $39 \AA$. The size of a polymer near a surface may be approximated as the Flory radius (Szleifer, 1996). More recent calculations based on de Gennes theory and molecular simulation have found that for PEG chains grafted onto lipid bilayers, the cross-sectional surface area "coverage" is actually smaller (Kenworthy et al., 1995; Kuhl et al., 1994; Rex et al., 1998). Specifically, Rex et al. found that the diameter of the cross-sectional coverage for PEG 2000 chains to be only approximately $18 \AA$, a more conservative number that we chose for our analysis.

We can categorize the identified epitopes (Moskalenko et al., 2000; Wobus et al., 2000) into ones actually containing one or more lysine residues, epitopes within $18 \AA$ of the nearest lysine residue, and epitopes with no nearby lysines. Table I summarizes the known epitopes and their straight-line distances to the nearest lysines, based on an AAV2 capsid

Table I. AAV2 neutralizing epitopes and their closest lysine residues.

\begin{tabular}{|c|c|c|c|c|}
\hline Epitope & Sequence & Lysines in epitope & Lysine position and (nearest distance to epitope) & References \\
\hline P33 & $241-260$ & 258 & 649 (5.5), 665 (7), 314 (8.6), 321 (11.3), 309 (14.7) & Moskalenko et al. (2000) \\
\hline P41-45 & $305-356$ & $309,314,321$ & $620(4), 649(5), 640(6.3), 688(9.6)$ & Moskalenko et al. (2000) \\
\hline P53 & $400-420$ & - & $\begin{array}{l}314(5), 309(6), 640(7.7), 312(9.2), 620(9.7), 649(10.3), 688(11.3) \\
620(9.7), 649(10.3), 688(11.3)\end{array}$ & $\begin{array}{l}\text { Moskalenko et al. (2000) } \\
\text { Moskalenko et al. (2000) }\end{array}$ \\
\hline P58 & $442-460$ & - & - & Moskalenko et al. (2000) \\
\hline P61-62 & $472-484$ & - & $507(9.7), 527(15.7)$ & Moskalenko et al. (2000) \\
\hline $\mathrm{P} 90$ & $697-716$ & 706 & $692(11), 544$ (11.53), $688(13)$ & Moskalenko et al. (2000) \\
\hline A20-1 & $271-280$ & - & $258(7.5), 649(5.1), 665(7.8)$ & Wobus et al. (2000) \\
\hline A $20-2$ & $369-378$ & - & $258(7.5), 649(11), 549$ (15), $314(18)$ & Wobus et al. (2000) \\
\hline D3-7 & $474-483$ & - & Same as P61-62 & Wobus et al. (2000) \\
\hline $\mathrm{C} 37-2$ & $492-503$ & - & 507 (3.4), 532 (3.4), 490 (11), 527 (11.7), 549 (16.6) & Wobus et al. (2000) \\
\hline A20-4 & $566-574$ & - & $527(4), 490(11.8), 532(12)$ & Wobus et al. (2000) \\
\hline C $37-3$ & $601-610$ & - & - & Wobus et al. (2000) \\
\hline B1 & $726-733$ & - & $688(13.4), 692(12)$ & Wobus et al. (2000) \\
\hline
\end{tabular}

The epitopes listed were identified by Moskalenko et al. (2000) and Wobus et al. (2000). The amino acid positions of the epitopes, as well as the positions of lysine residues within some epitopes, are listed. Finally, the positions of nearby lysines are listed, as well as their closest distance from the epitope (angstroms). Only lysines within $18 \AA$ are shown, as this distance is half of the estimated radius of gyration of a MW 2,000 PEG chain. Analysis was conducted with SwissPDB viewer. 
model assembled from the solved structure of VP2 (Xie et al., 2002b). Note that lysines likely differ in PEG reactivity, and some may not be PEGylated at even the highest polymer ratios. Only 3 out of 13 epitopes possess one or more lysine residues within the actual antigenic region. Although it is difficult to determine the $\mathrm{pK}_{\mathrm{a}}$ values, and therefore the relative reactivities, of lysines within a protein, the lysines in these three epitopes are likely to span a range of reactivities. $\mathrm{K} 309$ within epitope P41-45, which is adjacent to an arginine and may thus have a reduced $\mathrm{pK}_{\mathrm{a}}$ and higher reactivity, is likely to protect its epitope. K258 in epitope P33 and K314 in P41-45, surrounded by a mixture of polar and hydrophobic residues, may have moderate reactivities. By contrast, K321 in P41-45 and K706 in P90 are next to acidic residues and are thus likely to be in an unreactive, protonated state, leaving these regions of the capsid surface unprotected.

In addition, the epitopes C37-2, P33, and P41-45 are fairly well surrounded by lysines (Fig. 5 and Table I). By contrast, P61-62/D3-7 has adjacent lysines but is not as well encompassed. Finally, other epitopes are very distant from any lysine residues. For example, the closest lysine residues to the C37-3 epitope is $\sim 20 \AA$ away, whereas P58's closest lysine is $\sim 26 \AA$ away (Fig. 5). These dimensions suggest that if antibody binding to one of these latter epitopes is sufficient to inactivate the viral particles, then lysine PEGylation will
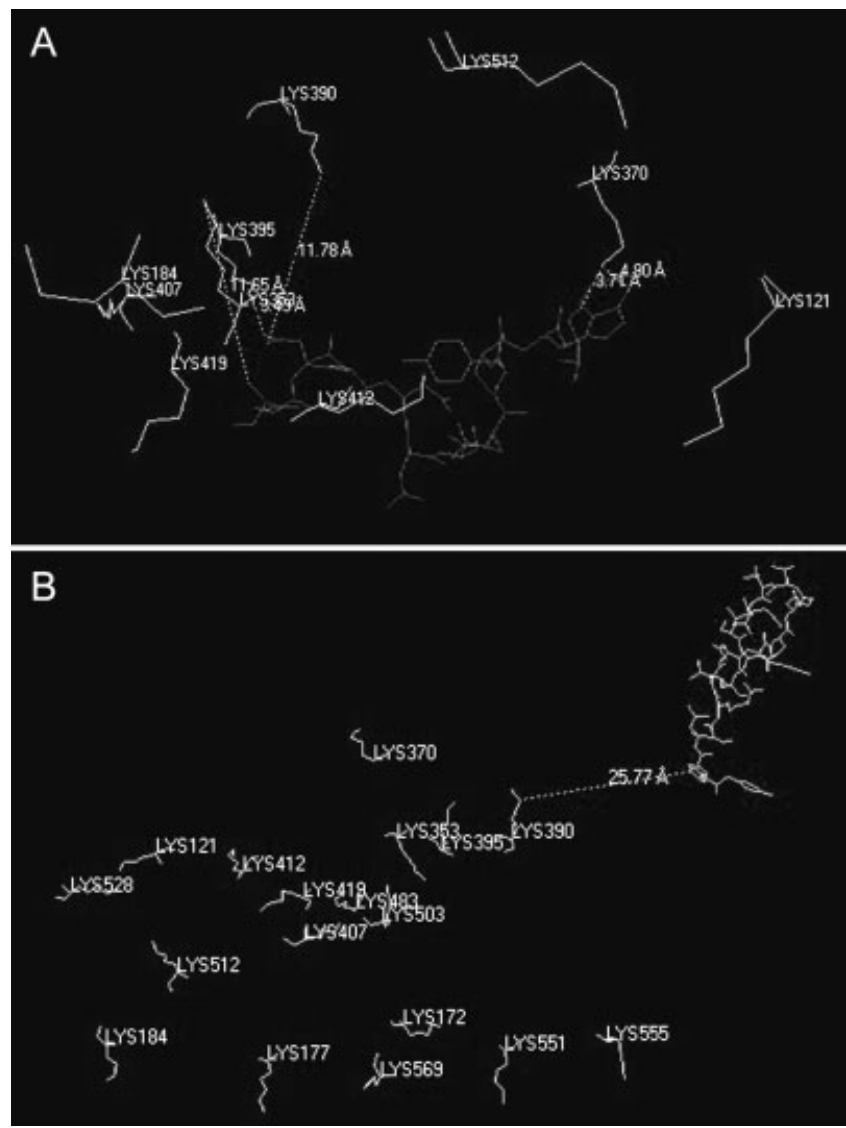

Figure 5. A: The C37-2 epitope is surrounded by lysine residues. Two residues (K305 and K330) reside especially close to this key epitope. B: By contrast, there are no lysines within 20 angstroms of the P58 epitope. be unlikely to prevent this neutralization. In this case, one attractive alternative may be engineering in lysine or cysteine residues flanking these regions to provide additional PEGylation sites.

We summarize by presenting a model for how PEGylation affects viral infectivity and antiserum protection (Fig. 6). We observed that infectivity was compromised above a key PEG:lysine level, though this critical conjugation ratio decreased as the molecular weight of the PEG chain increased. Steric coverage of key surface regions necessary for cellular infection, or the loss of key lysine residues could account for this drop. Even low levels of surface crosslinking with the larger PEG 20000 may rapidly block regions of the capsid necessary for interaction with target cells and thereby reduce infectivity, consistent with the transduction results (Fig. 2). The TEM results support this interpretation by showing that even at low polymer ratios, PEGylation conjugation had already significantly changed the particle properties (Fig. 4). By contrast, as more 2000 and 5000 molecular weight polymers (with free Flory radii of 39 and $63 \AA$ in solution, respectively) are conjugated to the surface, they may be small enough to avoid blocking regions important for viral infectivity, yet protect some important capsid features from antibody neutralization, potentially including the epitopes that lie close to lysine residues (Table I). As the critical conjugation ratio of these polymers is exceeded, however, there is a drop in infectivity (Fig. 2) accompanied by a physical alteration in particle properties (Fig. 4). This loss may be due to a combination of both steric blocking of regions important for viral infectivity, occurring even for the shorter

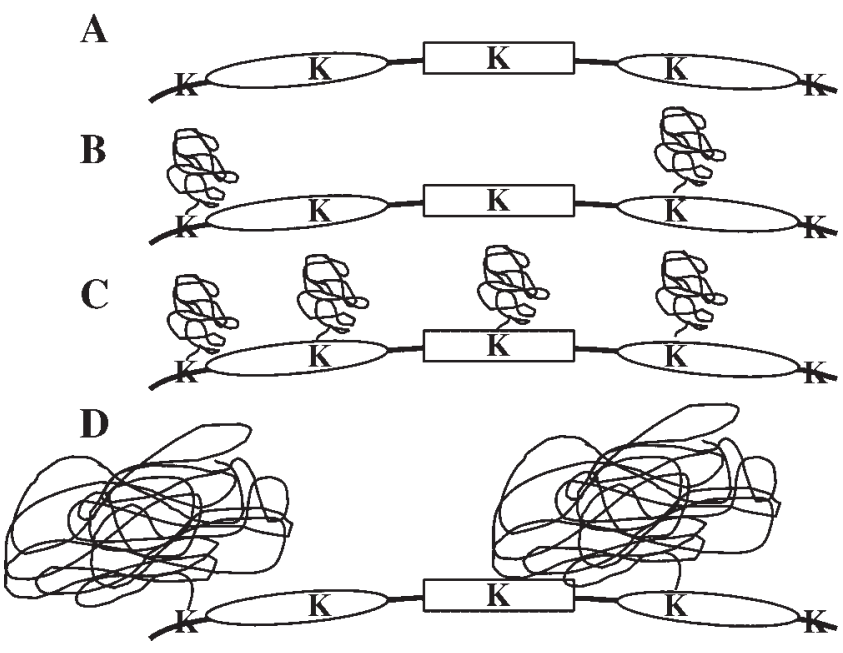

Figure 6. A: Model of the relationships between AAV PEGylation, infectivity, and protection from neutralization. Schematically, the viral surface has heparan sulfate binding domains (box) and neutralizing antibody epitopes (ovals), which are likely also regions important for viral transduction. B: For low MW PEG chains, at a low PEGylation molar ratio, lysines of lower reactivity become PEGylated, providing some level of shielding for the epitopes. C: Beyond the critical conjugation stoichiometry ratios, however, more lysines become conjugated with PEG, leading to reduced infectivity. D: Even at a relatively low molar ratio, larger PEG chains provides more shielding. As a result, they more readily block regions of the viral surface necessary for infection, leading to losses in infectivity before the virus is able to benefit from antibody protection. 
polymers at high PEG levels, as well as the PEGylation of key lysine residues within these regions (Kern et al., 2003; Opie et al., 2003; Wu et al., 2000) (Table I).

This initial study of AAV PEGylation examines the effects of polymer length and conjugation ratio on antibody neutralization. Our results demonstrate that antibody protection occurs within a narrow window of crosslinking ratios, and future efforts should focus on addressing the issue of the loss in infectivity just as the PEG is beginning to confer protection. If these losses are due to reaction at key lysines, then based on information of capsid locations tolerant to mutagenesis (Girod et al., 1999; Rabinowitz et al., 1999; Shi et al., 2001; Wu et al., 2000) new PEG attachments sites could be engineered into the vector to further enhance polymer protection of AAV gene delivery. Future work should include investigation of whether PEGylation can protect wild type or engineered capsids from immune neutralization in animal models.

We thank JT Koerber for critical feedback and Sharlene Dwinell for technical help. We also thank Reena Zalpuri and the U.C. Berkeley Electron Microscope Lab for their extensive help with image collection and analysis.

\section{References}

Afione SA, Conrad CK, Kearns WG, Chunduru S, Adams R, Reynolds TC, Guggino WB, Cutting GR, Carter BJ, Flotte TR. 1996. In vivo model of adeno-associated virus vector persistence and rescue. J Virol 70(5): $3235-3241$.

Alcantar NA, Aydil ES, Israelachvili JN. 2000. Polyethylene glycol-coated biocompatible surfaces. J Biomed Mater Res 51(3):343-351.

Bailon P, Palleroni A, Schaffer CA, Spence CL, Fung WJ, Porter JE, Ehrlich GK, Pan W, Xu ZX, Modi MW, Farid A, Berthold W, Graves M. 2001. Rational design of a potent, long-lasting form of interferon: A $40 \mathrm{kDa}$ branched polyethylene glycol-conjugated interferon alpha-2a for the treatment of hepatitis C. Bioconjug Chem 12(2):195-202.

Bueler H. 1999. Adeno-associated viral vectors for gene transfer and gene therapy. Biol Chem 380(6):613-622.

Chapman RG, Ostuni E, Takayama S, Holmlin RE, Yan L, Whitesides GM. 2000. Surveying for surfaces that resist the adsorption of proteins. J Am Chem Soc 122:8303-8304.

Croyle MA, Yu QC, Wilson JM. 2000. Development of a rapid method for the PEGylation of adenoviruses with enhanced transduction and improved stability under harsh storage conditions. Hum Gene Ther 11(12):17131722.

Croyle MA, Chirmule N, Zhang Y, Wilson JM. 2001. "Stealth" adenoviruses blunt cell-mediated and humoral immune responses against the virus and allow for significant gene expression upon readministration in the lung. J Virol 75(10):4792-4801.

Croyle MA, Chirmule N, Zhang Y, Wilson JM. 2002. PEGylation of E1deleted adenovirus vectors allows significant gene expression on readministration to liver. Hum Gene Ther 13(15):1887-1900.

Croyle MA, Callahan SM, Auricchio A, Schumer G, Linse KD, Wilson JM, Brunner LJ, Kobinger GP. 2004. PEGylation of a vesicular stomatitis virus $\mathrm{G}$ pseudotyped lentivirus vector prevents inactivation in serum. J Virol 78(2):912-921.

Duan D, Sharma P, Yang J, Yue Y, Dudus L, Zhang Y, Fisher KJ, Engelhardt JF. 1998. Circular intermediates of recombinant adeno-associated virus have defined structural characteristics responsible for long-term episomal persistence in muscle tissue. J Virol 72(11):8568-8577.
Edwards CK 3rd, Martin SW, Seely J, Kinstler O, Buckel S, Bendele AM, Ellen Cosenza M, Feige U, Kohno T. 2003. Design of PEGylated soluble tumor necrosis factor receptor type I (PEG sTNF-RI) for chronic inflammatory diseases. Adv Drug Deliv Rev 55(10):1315-1336.

Emoto K, Harris JM, Van Alstine JM. 1996. Grafting poly(ethylene glycol) epoxide to amino-derivatized quartz: Effect of temperature and $\mathrm{pH}$ on grafting density. Anal Chem 68:3751-3757.

Erles K, Sebokova P, Schlehofer JR. 1999. Update on the prevalence of serum antibodies (IgG and IgM) to adeno-associated virus (AAV). J Med Virol 59(3):406-411.

Fisher KD, Stallwood Y, Green NK, Ulbrich K, Mautner V, Seymour LW. 2001. Polymer-coated adenovirus permits efficient retargeting and evades neutralising antibodies. Gene Ther 8(5):341-348.

Flannery JG, Zolotukhin S, Vaquero MI, LaVail MM, Muzyczka N, Hauswirth WW. 1997. Efficient photoreceptor-targeted gene expression in vivo by recombinant adeno-associated virus. Proc Natl Acad Sci USA 94(13):6916-6921.

Flory PJ, Fisk J. 1966. Effect of volume exclusion on the dimensions of polymer chains. J Chem Phys 44:2243-2248.

Flotte TR, Afione SA, Zeitlin PL. 1994. Adeno-associated virus vector gene expression occurs in nondividing cells in the absence of vector DNA integration. Am J Respir Cell Mol Biol 11(5):517-521.

Gao GP, Alvira MR, Wang L, Calcedo R, Johnston J, Wilson JM. 2002. Novel adeno-associated viruses from rhesus monkeys as vectors for human gene therapy. Proc Natl Acad Sci USA 99(18):11854-11859.

Gao G, Alvira MR, Somanathan S, Lu Y, Vandenberghe LH, Rux JJ, Calcedo R, Sanmiguel J, Abbas Z, Wilson JM. 2003. Adeno-associated viruses undergo substantial evolution in primates during natural infections. Proc Natl Acad Sci USA 100(10):6081-6086.

Girod A, Ried M, Wobus C, Lahm H, Leike K, Kleinschmidt J, Deleage G, Hallek M. 1999. Genetic capsid modifications allow efficient retargeting of adeno-associated virus type 2. Nat Med 5(12):1438.

Halbert CL, Standaert TA, Wilson CB, Miller AD. 1998. Successful readministration of adeno-associated virus vectors to the mouse lung requires transient immunosuppression during the initial exposure. J Virol 72(12):9795-9805.

Halbert CL, Rutledge EA, Allen JM, Russell DW, Miller AD. 2000. Repeat transduction in the mouse lung by using adeno-associated virus vectors with different serotypes. J Virol 74(3):1524-1532.

Harris JM, Zalipsky S. 1997. Poly(ethylene glycol). Chemistry and biological applications. Washington, D.C.: American Chemical Society.

Herzog RW. 2004. AAV-mediated gene transfer to skeletal muscle. Methods Mol Biol 246:179-194.

Herzog RW, High KA. 1999. Adeno-associated virus-mediated gene transfer of factor IX for treatment of hemophilia B by gene therapy. Thromb Haemost 82(2):540-546.

Hildinger M, Auricchio A, Gao G, Wang L, Chirmule N, Wilson JM. 2001. Hybrid vectors based on adeno-associated virus serotypes 2 and 5 for muscle-directed gene transfer. J Virol 75(13):6199-6203.

Huttner NA, Girod A, Perabo L, Edbauer D, Kleinschmidt JA, Buning H, Hallek M. 2003. Genetic modifications of the adeno-associated virus type 2 capsid reduce the affinity and the neutralizing effects of human serum antibodies. Gene Ther 10(26):2139-2147.

Jeon SI, Andrade JD. 1991. Protein surface interactions in the presence of polyethylene oxide. 2. Effect of protein size. J Colloid Interf Sci 142: 159-166.

Jeon SI, Lee JH, Andrade JD, De Gennes PG. 1991. Protein surface interactions in the presence of polyehtylene oxide. 1. Simplified theory. J Colloid Interf Sci 142:149-158.

Kaspar BK, Erickson D, Schaffer D, Hinh L, Gage FH, Peterson DA. 2002a. Targeted retrograde gene delivery for neuronal protection. Mol Ther 5(1):50-56.

Kaspar BK, Vissel B, Bengoechea T, Crone S, Randolph-Moore L, Muller R, Brandon EP, Schaffer D, Verma IM, Lee KF, et al. 2002b. Adenoassociated virus effectively mediates conditional gene modification in the brain. Proc Natl Acad Sci USA 99(4):2320-2325.

Kaspar BK, Llado J, Sherkat N, Rothstein JD, Gage FH. 2003. Retrograde viral delivery of IGF-1 prolongs survival in a mouse ALS model. Science 301(5634):839-842. 
Kay MA, Manno CS, Ragni MV, Larson PJ, Couto LB, McClelland A, Glader B, Chew AJ, Tai SJ, Herzog RW, et al. 2000. Evidence for gene transfer and expression of factor IX in haemophilia B patients treated with an AAV vector. Nat Genet 24(3):257-261.

Kearns WG, Afione SA, Fulmer SB, Pang MC, Erikson D, Egan M, Landrum MJ, Flotte TR, Cutting GR. 1996. Recombinant adeno-associated virus (AAV-CFTR) vectors do not integrate in a site-specific fashion in an immortalized epithelial cell line. Gene Ther 3(9):748-755.

Kenworthy AK, Hristova K, Needham D, McIntosh TJ. 1995. Range and magnitude of the steric pressure between bilayers containing phospholipids with covalently attached poly(ethylene glycol). Biophys J 68(5): 1921-1936.

Kern A, Schmidt K, Leder C, Muller OJ, Wobus CE, Bettinger K, Von der Lieth CW, King JA, Kleinschmidt JA. 2003. Identification of a heparinbinding motif on adeno-associated virus type 2 capsids. J Virol 77(20): 11072-11081.

Kingshott P, Griesser HJ. 1999. Surfaces that resist bioadhesion. Curr Opin Solid State Mater Sci 4:403-412.

Kingshott P, Thissen H, Griesser HJ. 2002. Effects of cloud-point grafting, chain length, and density of PEG layers on competitive adsorption of ocular proteins. Biomaterials 23(9):2043-2056.

Kozlowski A, Harris JM. 2001. Improvements in protein PEGylation: Pegylated interferons for treatment of hepatitis C. J Control Release 72(1-3):217-224.

Kuhl TL, Leckband DE, Lasic DD, Israelachvili JN. 1994. Modulation of interaction forces between bilayers exposing short-chained ethylene oxide headgroups. Biophys J 66(5):1479-1488.

Lai K, Kaspar BK, Gage FH, Schaffer DV. 2003. Sonic hedgehog regulates adult neural progenitor proliferation in vitro and in vivo. Nat Neurosci 6(1):21-27.

Lee G, Schaffer DV. 2003. Engineering the surface properties of gene delivery vectors. Luo D, Saltzman WM, editors. New York: Kluwer Academic Publishers.

Luo M, Tsao J, Rossmann MG, Basak S, Compans RW. 1988. Preliminary $\mathrm{X}$-ray crystallographic analysis of canine parvovirus crystals. J Mol Biol 200(1):209-211.

Luxon BA, Grace M, Brassard D, Bordens R. 2002. Pegylated interferons for the treatment of chronic hepatitis C infection. Clin Ther 24(9):13631383.

Malik F, Delgado C, Knusli C, Irvine AE, Fisher D, Francis GE. 1992. Polyethylene glycol (PEG)-modified granulocyte-macrophage colonystimulating factor (GM-CSF) with conserved biological activity. Exp Hematol 20(8):1028-1035.

Malmsten M, Van Alstine JM. 1996. Adsortion of poly(ethlyene glycol) amphiphiles to form coatings which inhibit protein adsorption. J Coll Int Sci 177:502-512.

Manning WC, Zhou S, Bland MP, Escobedo JA, Dwarki V. 1998. Transient immunosuppression allows transgene expression following readministration of adeno-associated viral vectors. Hum Gene Ther 9(4):477485.

Miao CH, Nakai H, Thompson AR, Storm TA, Chiu W, Snyder RO, Kay MA. 2000. Nonrandom transduction of recombinant adeno-associated virus vectors in mouse hepatocytes in vivo: Cell cycling does not influence hepatocyte transduction. J Virol 74(8):3793-3803.

Moskalenko M, Chen L, van Roey M, Donahue BA, Snyder RO, McArthur JG, Patel SD. 2000. Epitope mapping of human anti-adeno-associated virus type 2 neutralizing antibodies: Implications for gene therapy and virus structure. J Virol 74(4):1761-1766.

Nakai H, Iwaki Y, Kay MA, Couto LB. 1999. Isolation of recombinant adeno-associated virus vector-cellular DNA junctions from mouse liver. J Virol 73(7):5438-5447.

O'Riordan CR, Lachapelle A, Delgado C, Parkes V, Wadsworth SC, Smith AE, Francis GE. 1999. PEGylation of adenovirus with retention of infectivity and protection from neutralizing antibody in vitro and in vivo. Hum Gene Ther 10(8):1349-1358.

Opie SR, Warrington KH Jr., Agbandje-McKenna M, Zolotukhin S, Muzyczka N. 2003. Identification of amino acid residues in the capsid proteins of adeno-associated virus type 2 that contribute to heparan sulfate proteoglycan binding. J Virol 77(12):69957006.

Peden CS, Burger C, Muzyczka N, Mandel RJ. 2004. Circulating anti-wildtype adeno-associated virus type 2 (AAV2) antibodies inhibit recombinant AAV2 (rAAV2)-mediated, but not rAAV5-mediated, gene transfer in the brain. J Virol 78(12):6344-6359.

Rabinowitz JE, Xiao W, Samulski RJ. 1999. Insertional mutagenesis of AAV2 capsid and the production of recombinant virus. Virology 265(2): 274-285.

Rabinowitz JE, Rolling F, Li C, Conrath H, Xiao W, Xiao X, Samulski RJ. 2002. Cross-packaging of a single adeno-associated virus (AAV) type 2 vector genome into multiple AAV serotypes enables transduction with broad specificity. J Virol 76(2):791-801.

Rex S, Zuckermann MJ, Lafleur M, Silvius JR. 1998. Experimental and Monte Carlo simulation studies of the thermodynamics of polyethyleneglycol chains grafted to lipid bilayers. Biophys J 75(6):2900-2914.

Roberts MJ, Bentley MD, Harris JM. 2002. Chemistry for peptide and protein PEGylation. Adv Drug Deliv Rev 54(4):459-476.

Rutledge EA, Halbert CL, Russell DW. 1998. Infectious clones and vectors derived from adeno-associated virus (AAV) serotypes other than AAV type 2. J Virol 72(1):309-319.

Samulski RJ, Chang LS, Shenk T. 1989a. Helper-free stocks of recombinant adeno-associated viruses: Normal integration does not require viral gene expression. J Virol 63:3822-3828.

Samulski RJ, Chang LS, Shenk T. 1989b. Helper-free stocks of recombinant adeno-associated viruses: Normal integration does not require viral gene expression. J Virol 63(9):3822-3828.

Sanftner LM, Suzuki BM, Doroudchi MM, Feng L, McClelland A, Forsayeth JR, Cunningham J. 2004. Striatal delivery of rAAV-hAADC to rats with preexisting immunity to AAV. Mol Ther 9(3):403-409.

Shi W, Arnold GS, Bartlett JS. 2001. Insertional mutagenesis of the adenoassociated virus type 2 (AAV2) capsid gene and generation of AAV2 vectors targeted to alternative cell-surface receptors. Hum Gene Ther 12(14):1697-1711.

Summerford C, Samulski RJ. 1998. Membrane-associated heparan sulfate proteoglycan is a receptor for adeno-associated virus type 2 virions. J Virol 72(2):1438-1445.

Sun JY, Anand-Jawa V, Chatterjee S, Wong KK. 2003. Immune responses to adeno-associated virus and its recombinant vectors. Gene Ther 10(11):964-976

Szleifer I. 1996. Statistical thermodynamics of polymers near surfaces. Curr Opin Coll Interf Sci 1:416-423.

Takeda S, Takahashi M, Mizukami H, Kobayashi E, Takeuchi K, Hakamata Y, Kaneko T, Yamamoto H, Ito C, Ozawa K, et al. 2004. Successful gene transfer using adeno-associated virus vectors into the kidney: Comparison among adeno-associated virus serotype 1-5 vectors in vitro and in vivo. Nephron Exp Nephrol 96(4):e119-e126.

Tenenbaum L, Chtarto A, Lehtonen E, Velu T, Brotchi J, Levivier M. 2004. Recombinant AAV-mediated gene delivery to the central nervous system. J Gene Med 6(Suppl 1):S212-S222.

Tsunoda S, Ishikawa T, Yamamoto Y, Kamada H, Koizumi K, Matsui J, Tsutsumi Y, Hirano T, Mayumi T. 1999. Enhanced antitumor potency of polyethylene glycolylated tumor necrosis factor-alpha: A novel polymer-conjugation technique with a reversible amino-protective reagent. J Pharmacol Exp Ther 290(1):368-372.

Veronese FM. 2001. Peptide and protein PEGylation: A review of problems and solutions. Biomaterials 22(5):405-417.

Veronese FM, Harris JM. 2002. Introduction and overview of peptide and protein pegylation. Adv Drug Deliv Rev 54(4):453-456.

Walz CM, Nakamura M, Fukunaga T, Jasiewicz Y, Edler L, Schlehofer JR, Tanaka Y. 2001. Reduced prevalence of serum antibodies against adenoassociated virus type 2 in patients with adult T-cell leukaemia lymphoma. J Med Virol 65(1):185-189.

Wobus CE, Hugle-Dorr B, Girod A, Petersen G, Hallek M, Kleinschmidt JA. 2000. Monoclonal antibodies against the adeno-associated virus type 2 (AAV-2) capsid: Epitope mapping and identification of capsid domains involved in AAV-2-cell interaction and neutralization of AAV-2 infection. J Virol 74(19):9281-9293. 
Wu P, Xiao W, Conlon T, Hughes J, Agbandje-McKenna M, Ferkol T, Flotte T, Muzyczka N. 2000. Mutational analysis of the adenoassociated virus type 2 (AAV2) capsid gene and construction of AAV2 vectors with altered tropism. J Virol 74(18):8635-8647.

Xiao X, Li J, McCown TJ, Samulski RJ. 1997. Gene transfer by adenoassociated virus vectors into the central nervous system. Exp Neurol 144(1):113-124.

Xiao W, Chirmule N, Berta SC, McCullough B, Gao G, Wilson JM. 1999. Gene therapy vectors based on adeno-associated virus type 1. J Virol 73(5):3994-4003.
Xie Q, Bu W, Bhatia S, Hare J, Somasundaram T, Azzi A, Chapman MS. 2002a. The atomic structure of adeno-associated virus (AAV-2), a vector for human gene therapy. Proc Natl Acad Sci USA 99(16):10405-10410.

Xie Q, Bu W, Bhatia S, Hare J, Somasundaram T, Azzi A, Chapman MS. 2002b. The atomic structure of adeno-associated virus (AAV-2), a vector for human gene therapy. Proc Natl Acad Sci USA 99(16):10405-10410.

Yoshioka Y, Tsutsumi Y, Ikemizu S, Yamamoto Y, Shibata H, Nishibata T, Mukai Y, Okamoto T, Taniai M, Kawamura M, et al. 2004. Optimal sitespecific PEGylation of mutant TNF-alpha improves its antitumor potency. Biochem Biophys Res Commun 315(4):808-814. 